\title{
Analisis Pengetahuan, Sikap, Dan Perilaku Anak Buah Kapal Deck Terhadap Penggunaan Personal Protective Equipment Di MV. Sendang Mas
}

\author{
Lestari,E.G.T ${ }^{\mathrm{a}}$, Hasugian, S. ${ }^{\mathrm{b}}$, Wahyuni, I.S. ${ }^{\mathrm{c}}$ \\ a,b,c Politeknik Pelayaran Surabaya \\ a Email: emaninggalih@gmail.com, \\ ${ }^{\text {b}}$ Email: sereati9880@gmail.com \\ 'Email: deryaagung0208@gmail.com
}

\begin{abstract}
ABSTRAK
Penelitian ini bertujuan untuk mengetahui pengetahuan, sikap, dan perilaku anak buah kapal deck terhadap penggunaan Personal Protective Equipment di MV. Sendang Mas. Serta untuk mengetahui kesesuaian pengetahuan, sikap dan perilaku anak buah kapal deck dengan aturan yang berlaku. Jenis penelitian yang penulis sajikan adalah jenis penelitian deskriptif dengan pendekatan kuantitatif. Dengan populasi 24 crew kapal MV. Sendang Mas dengan penarikan purposive sampling adalah anak buah kapal deck adapun jumlah sampel dalam penelitian ini adalah 9 responden. Pengambilan data diperoleh dari penyebaran angket kuisioner, hasil observasi terhadap anak buah kapal dan wawancara. Lokasi penelitian ini dilaksanakan ketika penulis sedang dalam melaksanakan praktek layar di kapal MV. Sendang Mas. Hasil penelitian menunjukkan bahwa anak buah kapal deck di MV. Sendang Mas mempunyai pengetahuan yang baik tentang Personal Protective Equipment dengan indikator pengetahuan menunjukkan rata-rata skor 3,44. Sikap yang baik tentang Personal Protective Equipment dengan indikator sikap menunjukkan rata-rata skor 3,33. Serta mempunyai perilaku yang baik, dengan penggunaan Personal Protective Equipment yang mencapai 98,7 \%. Pengetahuan, sikap, dan perilaku anak buah kapal deck belum maksimal dan belum sesuai dengan aturan Code of Save Working Practice for Merchant Seafarers dan SMM TE-SO2 tentang Prosedur Manajemen Keselamatan Kapal PT. Tirtamas Express.
\end{abstract}

Kata Kunci: Pengetahuan, Sikap, Perilaku, Personal Protective Equipment

\section{PENDAHULUAN}

Faktor utama dari kenyamanan kerja adalah keselamatan kerja, khususnya terkait dengan kecelakaan kerja. Kecelakaan bukanlah suatu peristiwa tunggal, tetapi merupakan hasil dari serangkaian penyebab yang saling berkaitan yang disebabkan oleh kelemahan pimpinan, pekerja, prosedur kerja yang tidak memadai, serta tindakan para pekerja yang tidak aman sehingga berakibat pada turunnya tingkat produktivitas kerja. Peralatan keselamatan merupakan elemen yang penting untuk semua aktivitas yang melibatkan manusia atau sebuah lokasi dengan aktivitas manusia di dalamnya.

Peralatan keselamatan merupakan pertolongan pertama jika terjadi sebuah kecelakaan atau keadaan darurat, sehingga dapat meminimalkan risiko yang ada.

Berdasarkan aturan Internasional Code of Safe Working Practice for Merchant Seafarers 2015 edition Amandment 2, December 20178.3 Regulation 10 bahwa pelaut harus mengenakan alat pelindung pribadi yang disediakan saat mereka melaksanakan tugas, dan mengikuti instruksi penggunaan yang tepat. Alat pelindung diri harus selalu diperiksa 
oleh pemakainya setiap kali sebelum digunakan. Dan pelaut harus mematuhi pelatihan yang mereka terima dalam penggunaan item pelindung, serta mengikuti instruksi penggunaannya.

Berdasarkan pengalaman saat praktek di MV. Sendang Mas ada beberapa anak buah kapal yang belum menggunakan Personal Protective Equipment sesuai prosedur yang telah ditetapkan. Pada tanggal 12 Desember 2018 saat kapal berlabuh di Makassar, anak buah kapal sedang bekerja mengetok karat di main deck sebelah kanan. Bosun terkena percikan karat di bagian mata, sehingga mata memerah. Hal ini disebabkan kacamata yang digunakan tidak kedap, tidak sesuai standar kacamata yang harus digunakan saat mengetok karat. Hal ini disebabkan karena kurangnya kedisiplinan dan kesadaran anak buah kapal akan pentingnya penggunaan Personal Protective Equipment untuk keselamatan diri sendiri dan orang lain.

Dengan terjadinya kecelakaan di bagian deck kapal, maka menandakan bahwa banyak anak buah kapal yang belum terbiasa menggunakan alat keselamatan yang benar saat bekerja. Oleh karenanya perlu adanya sosialisasi pembekalan ilmu kepada anak buah kapal, agar mereka menggunakan alat pelindung diri secara lengkap dan sesuai prosedur agar dapat bekerja dengan aman dan tercipta keselamatan dalam bekerja. Perusahaan perlu membuat aturan dan prosedur keselamatan kerja yang jelas, tegas, dan mengikat agar dapat dipahami dan diterapkan oleh semua anak buah kapal. Perlu adanya pengawasan yang ketat oleh Nakhoda selaku wakil dari Perusahaan. Nakhoda diharapkan dapat memberikan sanksi yang tegas kepada anak buah kapal yang melanggar dan dapat memberikan contoh kepada anak buah kapal untuk menggunakan Personal Protective Equipment secara lengkap dan sesuai prosedur.
Sebagai anak buah kapal, mereka juga harus memiliki kesadaran diri akan keselamatan diri sendiri dan orang lain saat bekerja di deck. Dengan menggunakan alat pelindung diri yang lengkap sesuai dengan pekerjaan yang sedang dikerjakan.

Tujuan dari penelitian ini adalah untuk mengetahui bagaimana pengetahuan, sikap, dan perilaku anak buah kapal deck di kapal MV. Sendang Mas tentang penggunaan personal protective equipment. Serta kesesuaian pengetahuan, sikap, dan perilaku anak buah kapal deck di MV. Sendang Mas dengan aturan yang berlaku.

Menurut Notoatmodjo (2003) Pengetahuan atau kognitif merupakan domain yang sangat penting dalam bentuk tindakan seseorang (overt behavior). Sementara sikap merupakan reaksi atau respon yang masih tertutup dari seseorang terhadap suatu stimulus atau objek. Manifestasi sikap tidak dapat dilihat langsung tetapi hanya dapat ditafsirkan terlebih dahulu dari perilaku yang tertutup. Sikap secara nyata menunjukkan konotasi adanya kesesuaian reaksi terhadap stimulus tertentu yang dalam kehidupan seharihari merupakan reaksi yang bersifat emosional terhadap stimulus sosial. Suatu sikap belum otomatis terwujud dalam suatu tindakan (overt behavior). Untuk terwujudnya sikap menjadi suatu perbuatan nyata diperlukan faktor pendukung atau suatu kondisi yang memungkinkan, antara lain fasilitas. Secara lebih operasional perilaku dapat diartikan suatu respon organisme atau seseorang terhadap rangsangan (stimulus) dari luar subjek tersebut.

Diperlukan kesesuaian antara pengetahuan, sikap, dan perilaku anak buah kapal untuk mencapai keselamatan di kapal. Hal ini sejalan dengan aturan Internasional Code of Save Working Practice for Merchant Seafarers Chapter 8 tentang Personal Protective Equipment, aturan 8.2 Persyaratan 
Umum: 1) Aturan 8.2.1 Perusahaan harus memastikan bahwa pelaut diberikan alat pelindung diri sesuai yang dibutuhkan. 2) Aturan 8.2.2 Sebagai aturan umum, alat pelindung diri harus disediakan tanpa biaya kepada pelaut. Pengecualian untuk perusahaan tertentu pelaut mungkin diminta untuk melakukannya berkontribusi pada biaya, atau ketika pelaut ingin memiliki peralatan yang melebihi minimum standar yang disyaratkan oleh undang-undang (misal desain yang lebih menarik). 3) Aturan 8.2.3 Perusahaan harus menentukan peralatan yang diperlukan untuk memastikan bahwa peralatan itu sesuai dan efektif untuk tugas yang dimaksud, dan memenuhi standar desain dan pembuatan. 4) Aturan 8.2.6 Perusahaan juga harus memastikan bahwa alat pelindung diri diperiksa dan dipelihara secara teratur. 5) Aturan 8.2.7 Semua pelaut yang menggunakan peralatan pelindung harus diinstruksikan dengan benar dan terlatih dalam penggunaannya. Diberikan pengarahan tentang resiko dan mengapa peralatan pelindung harus digunakan. 6) Aturan 8.2.8 Instruksi pabrikan harus dijaga agar tetap aman dan sesuai penggunaan. Alat pelindung diri harus dijaga kebersihannya dan harus didesinfeksi jika diperlukan karena alasan kesehatan.

Begitu pun dengan Chapter 8 Aturan 8.3 Tugas Pelaut: 1) Aturan 8.3.1 Pelaut harus mengenakan peralatan pelindung yang disediakan saat bekerja. 2) Aturan 8.3.2 alat pelindung diri harus selalu diperiksa oleh pemakai setiap kali sebelum digunakan. Pelaut harus mematuhi pelatihan yang mereka terima dalam penggunaan peralatan pelindung, dan ikuti instruksi pabrik untuk penggunaannya.

Berikut ini merupakan alat pelindung diri (Personal Protective Equipment) bagi crew kapal berdasarkan aturan code of Save
Working Practice for Merchant Seafarers 2015 edition - Amendment 2, December 2017): 1) Aturan 8.5 Head Protection. 2) Aturan 8.6 Hearing Protection. 3) Aturan 8.7 Face and Eye Protection. 4) Aturan 8.7 Respiratory Protective Equipment. 5) Aturan 8.9 Hand and Foot Protection. 6) Aturan 8.10 Protection from falls. 7) Aturan 8.11 Body Protection

\section{METODE}

Penelitian ini menggunakan metode analisis deskriptif dengan pendekatan kuantitatif. Adapun tujuan penelitian deskriptif dengan pendekatan kuantitatif ini adalah untuk menjelaskan suatu situasi yang hendak diteliti dengan dukungan studi kepustakaan sehingga lebih memperkuat analisa peneliti dalam membuat suatu kesimpulan. Dimana hasil penelitian diperoleh dari hasil perhitungan indikator-indikator variabel penelitian kemudian dipaparkan secara tertulis oleh penulis. Lokus penelitian dilaksanakan di atas Kapal MV. Sendang Mas.

Populasi yang dimaksud dalam penelitian ini adalah seluruh crew di kapal Sendang Mas yang berjumlah 24 Orang. Teknik penentuan sampel yang penulis gunakan adalah purposive sampling. Teknik purposive sampling yaitu teknik pengambilan sampel yang didasarkan atas ciri-ciri tertentu yang dipandang mempunyai sangkut paut yang erat dengan ciri-ciri populasi yang sudah diketahui sebelumnya. (Margono, 2005). Sehingga sampel yang digunakan dalam penelitian adalah anak buah kapal deck sebanyak 9 sampel.

Instrumen penelitian dapat digunakan sebagai alat pengumpul data atau informasi. Instrumen penelitian yang digunakan dalam penelitian ini adalah kuisioner, observasi, dan wawancara. 


\section{HASIL DAN PEMBAHASAN}

Hasil dan pembahasan berisi hasil-hasil penelitian dan pembahasannya. Tuliskan temuantemuan yang diperoleh dari hasil-hasil penelitian yang telah dilakukan dan harus ditunjang oleh data-data yang memadai. Hasil-hasil penelitian dan temuan harus bisa menjawab permasalahan di bagian pendahuluan.

Tabel 1 Hasil rata-rata skala pengetahuan

\begin{tabular}{|c|l|c|c|c|}
\hline No & Indikator & $\begin{array}{c}\text { Rata- } \\
\text { rata } \\
\text { Skor }\end{array}$ & $\begin{array}{c}\text { Skala } \\
\text { Interval }\end{array}$ & $\begin{array}{c}\text { Nilai } \\
\text { Skala }\end{array}$ \\
\hline 1. & $\begin{array}{l}\text { Indikator } \\
\text { Pengetahuan }\end{array}$ & 3,44 & $3,26-$ & $\begin{array}{c}\text { Sangat } \\
\text { Positif }\end{array}$ \\
\hline
\end{tabular}

Berdasarkan tabel 1 tentang hasil rata-rata perhitungan angket pengetahuan anak buah kapal deck di MV. Sendang Mas dengan skala likert. Dilihat dari data tersebut diketahui pada indikator pengetahuan bahwa pengetahuan anak buah kapal deck di MV. Sendang Mas adalah positif atau baik.

Anak buah kapal deck di MV. Sendang Mas telah mengetahui dengan baik fungsi utama Personal Protective Equipments adalah untuk melindungi diri dari potensi kecelakaan kerja. Mengetahui Personal Protective Equipments apa saja yang harus digunakan ketika bekerja harian (khususnya mengetok karat), saat olah gerak, dan saat bongkar muat di pelabuhan. Namun beberapa anak buah kapal di MV. Sendang Mas belum mengetahui tentang aturan yang melandasi penggunaan Personal Protective Equipments, baik Aturan Internasional maupun Standar Operasional Prosedur Perusahaan.

Tabel 2 Hasil rata-rata sikap

\begin{tabular}{|c|c|c|c|c|}
\hline No & Indikator & $\begin{array}{c}\text { Rata- } \\
\text { rata } \\
\text { Skor }\end{array}$ & $\begin{array}{c}\text { Skala } \\
\text { Interval }\end{array}$ & $\begin{array}{c}\text { Nilai } \\
\text { Skala }\end{array}$ \\
\hline 1. & $\begin{array}{c}\text { Indikator } \\
\text { Sikap }\end{array}$ & 3,33 & $\begin{array}{c}3,26- \\
4,00\end{array}$ & $\begin{array}{c}\text { Sangat } \\
\text { Positif }\end{array}$ \\
\hline
\end{tabular}

Berdasarkan Tabel 2 tentang hasil

https://doi.org/10.46484/db.v1i1.184 rata-rata perhitungan angket sikap anak buah kapal deck di MV. Sendang Mas dengan skala likert. Dilihat dari data tersebut diketahui pada indikator sikap bahwa sikap anak buah kapal deck di MV. Sendang Mas adalah positif atau baik. Anak buah kapal deck di MV. Sendang Mas bersedia untuk menggunakan Personal Protective Equipments secara benar dan sesuai prosedur, dan menggunakannya secara lengkap tidak hanya ketika mendapat pengawasan dari pimpinan. Anak buah kapal deck di MV. Sendang Mas juga menyetujui jika setiap penerimaan crew harus diberikan penyuluhan/briefing terkait keselamatan kerja. Anak buah kapal deck juga menyetujui jika Nakhoda harus menginspeksi tempat kerja untuk meminimalisir kecelakaan kerja. Namun, anak buah kapal deck di MV. Sendang Mas kurang setuju jika anak buah kapal yang tidak menggunakan Personal Protective Equipments harus diberikan sanksi.

Tabel 3 Rekapitulase persentase penggunaan Personal Protective Equipment

\begin{tabular}{|c|l|c|c|}
\hline No & $\begin{array}{c}\text { Personal } \\
\text { Protective } \\
\text { Equipments }\end{array}$ & $\begin{array}{c}\text { Rata- } \\
\text { rata } \\
(\boldsymbol{\%})\end{array}$ & Nilai \\
\hline 1. & Safety Helmet & $99,2 \%$ & Positif \\
\hline 2. & Safety Googles & $96,5 \%$ & Positif \\
\hline 3. & Ear Plug & $100 \%$ & Positif \\
\hline 4. & Masker & $100 \%$ & Positif \\
\hline 5. & Safety Gloves & $94,4 \%$ & Positif \\
\hline 6. & Wearpack & $100 \%$ & Positif \\
\hline 7. & Safety Shoes & $99,8 \%$ & Positif \\
\hline 8. & Safety Harness & $100 \%$ & Positif \\
\hline
\end{tabular}

Berdasarkan Tabel 3 tentang hasil rata-rata persentase perilaku anak buah kapal deck di MV. Sendang Mas dengan observasi. Dilihat dari data tersebut diketahui pada indikator perilaku bahwa perilaku anak buah kapal deck di MV. Sendang Mas adalah positif atau baik.

Anak buah kapal deck di MV. Sendang Mas menggunakan ear plug, masker, wearpack, safety harness di setiap pekerjaan yang mewajibkan menggunakannya dengan persentase $100 \%$. Penggunaan safety helmet masih 
belum maksimal dengan persentase 99,2 \% karena masih ada anak buah kapal yang tidak menggunakan safety helmet pada pekerjaan mengetok karat. Penggunaan safety googles juga masih belum maksimal dengan persentase 96,5 \% karena masih ada anak buah kapal yang tidak menggunakan safety googles yaitu pada pekerjaan olah gerak kapal meliputi kegiatan anchor. Penggunaan safety gloves masih belum maksimal dengan persentase 94,4\% karena masih ada anak buah kapal yang tidak menggunakan safety gloves yaitu saat kegiatan mooring, anchor, dan mengawasi bongkar muat. Dan terakhir penggunaan safety shoes dengan persentase 99,8 \% karena masih ada anak buah kapal yang tidak menggunakan safety shoes yaitu saat kegiatan mengawasi bongkar muat.

\section{SIMPULAN}

Dari hasil penelitian yang dilakukan di MV. Sendang Mas tentang penggunaan Personal Protective Equipment pada pekerjaan di deck MV. Sendang Mas, dapat di tarik beberapa kesimpulan sebagai berikut : 1) Anak buah kapal deck di MV. Sendang Mas mempunyai pengetahuan yang baik tentang Personal Protective Equipment dengan indikator pengetahuan menunjukkan rata-rata skor 3,44. 2) Anak buah kapal deck di MV. Sendang Mas mempunyai sikap yang baik tentang Personal Protective Equipment dengan indikator sikap menunjukkan rata-rata skor 3,33. 3) Anak buah kapal deck di MV. Sendang Mas mempunyai perilaku yang baik, dengan penggunaan Personal Protective Equipment yang mencapai 98,7 \%. 3) Kesesuaian pengetahuan, sikap, dan perilaku anak buah kapal deck dengan aturan yang berlaku: a) Anak buah kapal deck kapal MV. Sendang Mas memiliki pengetahuan yang baik berkaitan dengan Personal Protective Equipment.
Namun perlu ditingkatkan pengetahuan mengenai aturan Internasional Code of Safe Working Practice for Merchant Seafarers dan Standar Operasional Prosedur Perusahaan SMM TE-S02 tentang Prosedur Manajemen Keselamatan Kapal. b) Hasil skor skala sikap beberapa anak buah kapal masih ada yang belum maksimal. Hal ini belum sesuai dengan Standar Operasional Prosedur Perusahaan pada SMM TE-S02 bahwa Perwira harus memastikan peraturan ini telah dipatuhi oleh seluruh anak buah kapal kapal. Dan pada Internal Memo yang ditujukan kepada Nakhoda disebutkan bahwa sanksi yang tegas akan diberikan kepada siapa saja yang tidak mengindahkan Internal Memo. c) Persentase penggunaan Personal Protective Equipments juga belum maksimal karena masih ada pemakaian Personal Protective Equipments yang belum mencapai $100 \%$. Hal ini belum sesuai dengan aturan Internasional Code of Safe Working Practice for Merchant Seafarers Chapter 8 Aturan 8.3.1 bahwa pelaut harus mengenakan peralatan pelindung yang disediakan saat bekerja. Dan pada SMM TE-S02 tentang Prosedur Manajemen Keselamatan Kapal pada aturan nomor 3 dan 4 disebutkan bahwa Awak kapal diharuskan menggunakan perlengkapan dan pakaian yang sesuai dengan jenis pekerjaan yang dilakukannya. Setiap awak kapal diharuskan menggunakan sepatu keselamatan. Awak kapal dilengkapi dan harus menggunakan pakaian dan perlengkapan pelindung yang tepat seperti kaca mata pelindung mata, safety helmet dan sarung tangan bila melakukan pekerjaan untuk mencegah kecelakaan kerja.

\section{DAFTAR PUSTAKA}

Anggoro, M. T. (2008). Metode Penelitian. Jakarta: Universitas terbuka. 
Arikunto, S. (2006). Prosedur Penelitian Suatu Pendekatan Praktek. Jakarta: Rinika Cipta

'Code of Safe Working Practices for Merchant Seafarers' 2015. London: TSO.

'Convention Concerning the Prevention of Occupational Accident to Seafarers' 1973. Geneva.

'Conference of Parties to the International Convention on Standards of Training, Certification and Watchkepping for Seafarers, 1978' 2010. English: IMO.

International Management Code for the Safe Operations of Ships and for Pollution Prevention (ISM Code)' 2015.

KBBI.2012 https://kbbi.web.id/guna Diakses pada tanggal 30 Januari 2018.

Kumar, R. (2011). Research Methodology. London.

Margono, S. (2005). Metodologi Penelitian Pendidikan. Jakarta: Rineka Cipta.

Notoatmodjo,S. 2007. Promosi Kesehatan dan Ilmu Perilaku. Jakarta : Rineka Cipta.

Sumani. (2008, November 21). Showmany's Blog. Retrieved April 4, 2018, from Showmany wordpress:

https://showmany.wordpress.com/

Sugiyono. 2013. Metode Penelitian Pendidikan Pendekatan Kuantitatif, Kualitatif, dan $R \& D$. Bandung: Alfabeta.

Zakky. (2018, Juni 3). Pengertian analisis menurut para ahli. Retrieved Januari 23, 2020, from Zona Referensi: https://www.zonareferensi.com/pe ngertian-analisis-menurut-paraahli-dan-secara-umum 